\title{
Evidence for sustained elevation of IL- 6 in the CNS as a key contributor of depressive-like phenotypes
}

\author{
SJ Sukoff Rizzo ${ }^{1,2}$, SJ Neal' ${ }^{1}$, ZA Hughes ${ }^{1}$, M Beyna ${ }^{1}$, S Rosenzweig-Lipson ${ }^{1,4}$, SJ Moss ${ }^{2,3}$ and NJ Brandon ${ }^{1,5}$
}

There is compelling clinical literature implicating a role for cytokines in the pathophysiology of major depressive disorder (MDD).

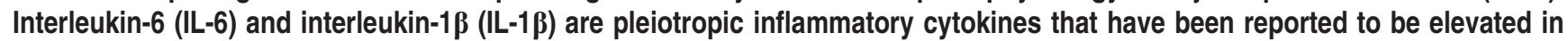
patients with MDD. The present studies were undertaken to investigate the relationship between IL- 6 and IL-1 $\beta$ in animal models of depressive-like behavior. Analysis of brain tissue homogenates in the cortex of rats subjected to chronic stress paradigms revealed elevated levels of IL- 6 protein in the absence of elevations in IL-1ß. Central administration of recombinant mouse IL- 6 produced depressive-like phenotypes in mice, which were not accompanied by IL-1ß-induced increases in the brain tissue or IL-1ß-related sickness behavior typical of a general central nervous system inflammatory response. Systemic administration of fluoxetine in the presence of centrally administered IL- 6 failed to produce the expected antidepressant-like response in mice relative to sham-infused controls. Further, administration of fluoxetine to mice with endogenous overexpression of brain IL-6 (MRL/MpJ-Fas ${ }^{\text {LPR/LPR }}$ (LPR mice)) failed to produce the expected antidepressant-like effect relative to fluoxetine-treated control mice (MRL/MpJ ${ }^{+l+}$ ). Interestingly, blockade of IL- 6 trans-signaling by coadministration of a gp130/Fc monomer or an antimouse IL- 6 antibody with IL- 6 prevented the IL- 6 -induced increases in immobility time as well as attenuated IL- 6 -induced increases of protein in the cortex. Taken together, these data indicate that elevations in IL-6 may have a pathophysiological role underlying depression and more specifically resistance to current classes of antidepressant medications and suggest that modulation of the IL- 6 signaling pathway may have therapeutic potential for treatment-resistant depression.

Translational Psychiatry (2012) 2, e199; doi:10.1038/tp.2012.120; published online 4 December 2012

\section{Introduction}

The cytokine hypothesis of depression, initially proposed by Smith $^{1}$ and later by Maes ${ }^{2}$ nearly two decades ago as a result of observations of increased inflammatory markers in the blood of chronically depressed patients, was at that time overshadowed by the advancement and success of selective serotonin reuptake inhibitors and other monoaminergic-based treatments for depression. In light of emerging data from clinical trials such as the 'Sequenced Treatment Alternatives to Relieve Depression' (STAR*D), which indicate that a substantial number of patients $(\sim 30 \%)$ remain unresponsive to standard, mainly monoaminergic-based therapies, there is a great urgency to understand treatment-resistant depression and develop new alternative therapeutics. ${ }^{3,4}$ Understanding the role of cytokines in the pathophysiology of depression may also explain some of the underlying causes for treatmentresistant depression. Clinical evidence supports a neuroimmune hypothesis of depression. In particular, the proinflammatory cytokines interleukin-1 $\beta$ (IL-1 $\beta$ ) and IL-6 have primarily been reported to be elevated in the serum or plasma of depressed patients, both with comorbid inflammatory disease and in the otherwise medically healthy. ${ }^{5-10}$ Although many neuroimmune factors have been implicated in depressive disorders, a survey of the clinical literature points to elevations of IL-6 as the most consistent finding across studies. ${ }^{9-15}$ Some of the most compelling data demonstrate: (a) elevations of IL- 6 in the absence of increased IL-1 $\beta$; (b) elevated levels of IL-6 in the cerebrospinal fluid and plasma of suicide attempters with a diagnosis of major depressive disorder (MDD) relative to controls; (c) increased plasma IL-6 levels associated with patients who are refractory to selective serotonin reuptake inhibitor or serotonin-norepinephrine reuptake inhibitor treatment; (d) normalization of elevated IL-6 levels in MDD patients following successful antidepressant treatment; and (e) IL-6 levels remaining elevated in the plasma of MDD patients who fail to respond to antidepressant therapy, all suggesting a potential role for IL-6 in treatmentresistant depression. ${ }^{5,9,16-22}$

Although an overwhelming amount of clinical evidence implicates IL-6 as an important mediator of MDD, there is little preclinical corroboration. To date, the preclinical studies of cytokine-induced depressive behavior have largely focused on administration of the bacterial endotoxin lipopolysacchride (LPS) or the proinflammatory cytokine IL-1 $\beta$. In rodents, it has been widely reported that LPS and IL-1 $\beta$ administered either centrally or peripherally induce depressive-like behaviors with accompanying increases in 'sickness behavior' and elevations in cytokines, such as IL-1 $\beta$, IL- 6 and tumor necrosis

\footnotetext{
${ }^{1}$ Neuroscience Research Unit, Pfizer Research and Development, Cambridge, MA, USA; ${ }^{2}$ Department of Neuroscience, Pharmacology and Physiology, University College London, London, UK and ${ }^{3}$ Department of Neuroscience, Tufts University School of Medicine, Boston, MA, USA

Correspondence: Dr SJ Sukoff Rizzo, Neuroscience Research Unit, Pfizer Global Research and Development, 700 Main Street, Cambridge, MA 02139, USA.

E-mail: Stacey.Rizzo@ pfizer.com.

${ }^{4}$ Current address: IVS Consulting East Brunswick, NJ, USA.

${ }^{5}$ Current address: Astra Zeneca Neuroscience Cambridge, MA, USA.

Keywords: CNS; cytokines; depression; IL-6; IL-1 $\beta$; rodents

Received 5 October 2012; accepted 10 October 2012
} 
factor- $\alpha{ }^{23-28}$ Sickness behavior refers to the repertoire of behavioral changes that develops in sick humans and animals during the course of infection. Along with the typical immune response to sickness, which includes fever, sick individuals demonstrate reduced appetite, hypoactivity, decreased social activity, significant changes in sleep patterns, an inability to experience pleasure (anhedonia), an increased sensitivity to painful stimuli and memory impairment. ${ }^{29-36}$ These behaviors are similar to symptoms observed in MDD based on the criteria from the Diagnostic and Statistical Manual version IV and have been documented in patients receiving cytokine treatment for inflammatory diseases such as hepatitis. ${ }^{37,38}$ Although the LPS and IL-1 $\beta$-induced models have historically been used to understand the relationship of cytokines and the sickness and depressive-like behavioral states, and often demonstrate IL-6 inductions as part of the nonspecific 'cytokine storm', which accompanies the well-documented behavioral effects, there still remains limited and conflicting evidence for a specific and direct role of IL-6. ${ }^{39-44}$ Interestingly, preclinical studies employing stressors (that is, restraint, inescapable shock, social defeat) to induce depressive-like behaviors in rodents often demonstrate an increase in IL-6 that accompanies the depressive-like phenotype. ${ }^{45-50}$ The primary hypothesis we have explored in this current work is that sustained elevation of IL-6 in the central nervous system (CNS) results in a depression phenotype that may be relevant pathology for treatmentresistant depression. Through using a combination of stressinduced models of depression, pharmacological and genetic models of elevated IL- 6 and multimodal therapeutic strategies, we have been able to demonstrate the relevance of IL-6 in preclinical models of depression.

\section{Materials and methods}

Animals. All experiments were performed in accordance with the specifications of the National Institutes of Health Guide for the Care and Use of Laboratory Animals (Pub. 8523, rev 1996) and under the approval of the Institutional Animal Care and Use Committee (IACUC). Experiments were conducted in an AAALAC-accredited facility maintained on a 12-h light/dark cycle (lights on at $0600 \mathrm{~h}$ ) with food and water provided ad libitum. Behavioral experiments were conducted during the light cycle between the hours of 0800-1700. Adult male Sprague-Dawley rats (Charles River Laboratories, Wilmington, MA, USA) were used for studies investigating stress-induced behavioral and cytokine responses. Adult male Swiss Webster mice (Charles River Laboratories) were used for studies evaluating exogenous administration of IL-1 $\beta$ or IL-6. For studies evaluating effects of endogenous overexpression of IL-6, male MRL/MpJ-Fas ${ }^{\mathrm{LPR} / \mathrm{LPR}}$ (LPR) mice and $\mathrm{MRL} / \mathrm{MpJ}^{+/+}(\mathrm{MRL})$ wild-type (WT) controls were used (Jackson Laboratories, Bar Harbor, ME, USA). All subjects were acclimated to the facility for a minimum of 1 week before experiments. Intact female C57BI6/J mice (Jackson Laboratories) were maintained in a separate housing room and used as noncontact stimulus females only during social behavior testing.

Learned helplessness. Learned helplessness was assessed in Sprague-Dawley rats in an escape-avoidance paradigm following exposure to inescapable footshock. Briefly, on day 1 subjects were sequestered to one side of a shuttle box (Med Associates, St Albans, VT, USA) and were administered a series of inescapable footshocks (60 shocks, $0.8 \mathrm{~mA}$, $15 \mathrm{~s}$ duration, 2-s intertrial interval) paired with a light cue and audible tone. Sham controls were exposed to the chambers but did not receive any footshocks or cues. On day 2, all subjects were assessed for helpless behavior in a 30-trial active-avoidance task (see Supplementary Information for detailed methods).

Social competition paradigm of dominant-submissive behavior. The social competition paradigm is similar to the procedure we reported previously, which takes advantage of the natural dominant-submissive relationship formed between a pair of male conspecifics. ${ }^{51}$ Briefly, pair-housed subjects (non food-restricted) were trained individually in operant chambers (Med Associates) to anticipate the presentation of a palatable reward (sugar pellet; BioServ, Frenchtown, NJ, USA) following a series of stimulus light cues. During the testing phase, both cagemates were placed within the operant chamber and assessed for dominantsubmissive behavior by a trained observer. The rat within the pair that obtained the food pellet was declared the winner and the other rat the loser. Dominance was expressed as the rat within each pair that consistently demonstrated the dominance of wins ( $>60 \%$ ) in daily sessions over the course of a 6-week period (see Supplementary Information for detailed methods).

Central administration of IL-1 $\beta$ and IL-6. Recombinant mouse IL-1 $\beta$ (R\&D Systems, Minneapolis, MN, USA) and recombinant mouse IL-6 (EBiosciences, San Diego, CA, USA) were diluted in artificial CSF containing $0.1 \%$ bovine serum albumin (BSA) as carrier protein. Proteins were injected directly into the brain $(2-3 \mu \mathrm{l}$; intracerebroventricularly) of noncannulated mice under isoflurane anesthesia as previously described and later confirmed in intracerebroventricularly (i.c.v.) cannulated mice (right lateral ventricle; Charles River Laboratories, Surgical Services Department). ${ }^{52}$ For cannulated mice, the rate of infusion was $1.5 \mu \mathrm{min}^{-1}$ and injection cannulae were maintained in place for an additional minute at the conclusion of the infusion. Antagonism experiments evaluating anti-IL-6 antibody (BD Pharmingen, San Jose, CA, USA) or soluble gp130 Fc chimera (R\&D Systems) (diluted in artificial CSF $+0.1 \% \mathrm{BSA}$ ) were conducted in only i.c.v. cannulated mice as were antagonism experiments evaluating the IL-1 receptor antagonist (IL-1RA) (R\&D Systems) (reconstituted in phosphate-buffered saline (PBS)).

Assessment of sickness behavior. A trained observer blind to the treatment conditions observed and scored the absence or presence of the following four behaviors in individually housed mice: hypoactivity, ptosis, curled body posture and piloerection. A cumulative score of 0 (no behavior observed) to 4 (all four behaviors observed) was assessed for each individual mouse.

Tail suspension test. The tail suspension test used is a variant of a procedure described previously. ${ }^{53}$ Briefly, 
subjects were suspended by their tails with tape to a flat bar for $6 \mathrm{~min}$ in duration (Med Associates). Immobility time was automatically recorded (Med PC software, St Albans, VT, USA).

Forced swim test. Subjects were placed into individual tanks $\left(33 \mathrm{~cm}\right.$ height $\times 10 \mathrm{~cm}$ diameter; $25 \pm 0.5^{\circ} \mathrm{C}$ water temperature) for a 6-min test period. Immobility time (floating) was recorded via automated cameras connected to an interface and computer and analyzed using BiObserve software (St Augustin, Germany).

Social interaction paradigm. Social behavior was assessed in male Swiss Webster mice $24 \mathrm{~h}$ after central administration of IL-6 $(1 \mu \mathrm{g})$ or vehicle control in the presence of females similar to methods described previously. ${ }^{54}$ Briefly, male test subjects were individually acclimated to the novel test cage for $30 \mathrm{~min}$ followed by an additional $30 \mathrm{~min}$ to the presence of two wire corrals (www.kitchen-plus.com, no. 31570). The trial began when a stimulus female was placed into one of the corrals and the empty corral was removed. A trained observer scored latency to first investigation and total investigation time for a 5-min observation period. Investigation time consisted of the following measurements: direct nose-to-nose contact of male to female, male forepaw contact (reach) to female, sniff or reach to corral floor or to any portion of the female external to the corral (for example, her tail).

Protein extraction. Brain tissue was collected following decapitation of anesthetized animals under isoflurane anesthesia, dissected in cold PBS and stored at $-80^{\circ} \mathrm{C}$. Frozen tissues were thawed in cold lysis buffer containing the following in PBS: $3 \%$ of $5 \mathrm{M} \mathrm{NaCl}, 2 \%$ of $1 \mathrm{M}$ Tris-buffered saline, $0.2 \%$ of $0.5 \mathrm{~m}$ ethylenediaminetetraacetic acid (EDTA), $0.2 \%$ of $0.5 \mathrm{~m}$ ethylene glycol tetraacetic acid (EGTA), $1 \%$ of Triton X-100, protease inhibitor tablets (Roche, Indianapolis, IN, USA, no. 04693116001) and $0.1 \%$ sodium dodecyl sulfate (SDS). For enzyme-linked immunosorbent assay (ELISA), the cortex (minus the cerebellum and olfactory bulbs) was homogenized in $1 \mu \mathrm{l}$ buffer per $1 \mu \mathrm{g}$ tissue wet weight. For western blot, the hippocampus and frontal cortex were homogenized in $200 \mu \mathrm{l}$ of complete lysis buffer. Homogenates were centrifuged at $15000 \mathrm{~g}$ for $20 \mathrm{~min}$ at $4^{\circ} \mathrm{C}$ and supernatants stored at $-80^{\circ} \mathrm{C}$.

Multiplex cytokine ELISA. Custom multiplex ELISA kits were purchased from Meso-Scale Devices (Gaithersburg, MD, USA). The standard manufacturer's protocol was modified to optimize for the detection of cytokines in the brain tissue by the addition of fresh protease inhibitors to thawing homogenates, and increasing the sample aliquot to $50 \mu \mathrm{l}$ (in duplicate) as well as extending the sample incubation time from 2 to $4 \mathrm{~h}$. All samples were normalized for total protein (BCA kit, Thermo Scientific, Rockford, IL, USA). A standard curve was generated for IL-1 $\beta$ and IL- 6 based on the standards provided.

SDS-PAGE and western blotting of IL-6. Reducing agents (NuPAGE, no. NP0004, Invitrogen, Grand Island, NY, USA) and loading buffer were added to samples and heat treated for $3 \mathrm{~min}\left(90^{\circ} \mathrm{C}\right)$ before loading. A total of $30-50 \mu \mathrm{g}$ of total protein were loaded in each lane $(5 \mu \mathrm{g}$ purified IL- 6 was used as loading control; EBiosciences, no. 34-8061). Protein samples were separated by SDS-PAGE gel electrophoresis (Invitrogen; 4-12\% Bis-Tris) in running buffer, washed in Tris-buffered saline with Tween-20 and transferred to a nitrocellulose membrane. Following successful transfer, membranes were cut at the $\sim 28 \mathrm{kDa}$ band, which allowed us to simultaneously probe for the protein of interest (IL-6 at $\sim 21 \mathrm{kDa}$ ) and the control protein (actin at $\sim 45 \mathrm{kDa}$ ) on the same gel (within sample control). Membranes were blocked with blocking buffer (Pierce SuperBlock, Thermo Scientific, Rockford, IL, USA no. 37517, + 0.1\% Tween-20) followed by incubation overnight at $4{ }^{\circ} \mathrm{C}$ with primary antibodies diluted in blocking buffer (IL-6 1:200 (BD Pharmingen), no. 554400; actin 1:10000 (Sigma, St Louis, MO, USA), no. A2066). Membranes were then washed in Tris-buffered saline with Tween-20 and incubated with horse radish peroxidaseconjugated anti-Ig secondary antibodies (Jackson ImmunoResearch, West Grove, PA, USA) at a dilution of 1:10000 in blocking buffer for $1 \mathrm{~h}$ at room temperature. Proteins were visualized using western blotting chemiluminescence reagents (ThermoScientific) and exposed to autoradiographic film. The product was analyzed by densitometry using the Quantity One 1-D Analysis software (Bio-Rad, Hercules, CA, USA).

Statistical analysis. Behavioral data are expressed as mean \pm s.e.m. Data were analyzed using a one-way analysis of variance (ANOVA) (treatment) or two-way ANOVA (treatment $\times$ pretreatment), (treatment $\times$ strain) or (treatment $\times$ time) depending upon the experimental design. A two-way ANOVA with repeated measures was used to analyze data of which time was a factor. ANOVA was followed by planned post hoc comparisons using Bonferroni's post hoc test. Significance was achieved at $P<0.05$.

\section{Results}

Depressive-like phenotypes are associated with elevated protein levels of IL- 6 in the brain in the absence of elevated levels of IL-1ß. Inescapable footshock resulted in $77 \%$ of subjects demonstrating learned helpless behavior ( $\geqslant 50 \%$ escape failures) during the test day relative to $23 \%$ of subjects exposed to inescapable footshock that did not become helpless. One-way ANOVA with a Bonferroni's post hoc test revealed that rats subjected to inescapable footshock that became helpless demonstrated a mean failure rate of $90 \pm 4.385 \%$ relative to a mean failure rate of $30 \pm 12.00 \%$ in nonshocked controls $(P<0.001$; Figure 1a). Further analysis of the mean failure rate of rats subjected to inescapable shock that did not become helpless (resilient) revealed a mean failure rate of $14 \pm 8.72 \%$. Analysis of IL-6 protein levels by one-way ANOVA from cortex homogenates revealed a nonsignificant increase in helpless subjects relative to sham controls $(\mathrm{F}(2,10)=2.235 ; \quad P>0.05$; Figure 1b) with planned Bonferroni's post hoc comparisons across groups revealing a reduction in IL-6 levels in the resilient group relative to the helpless group $(P=0.05)$. 
a

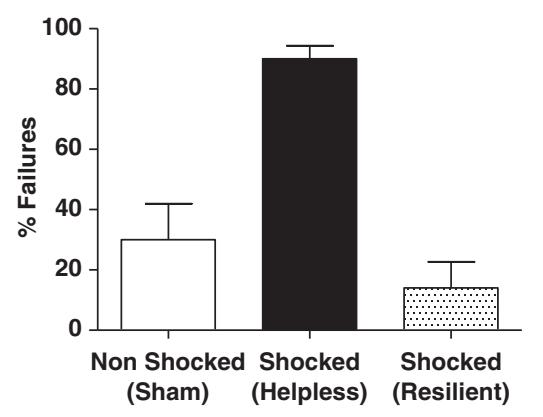

b

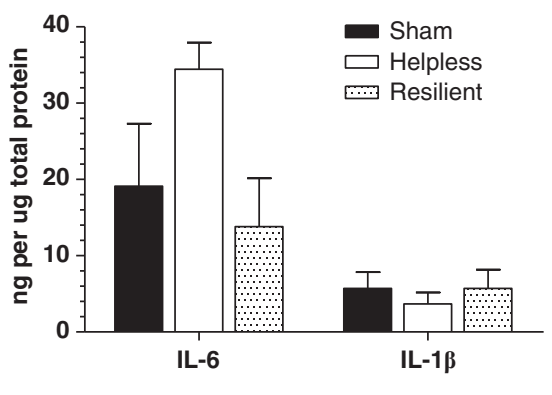

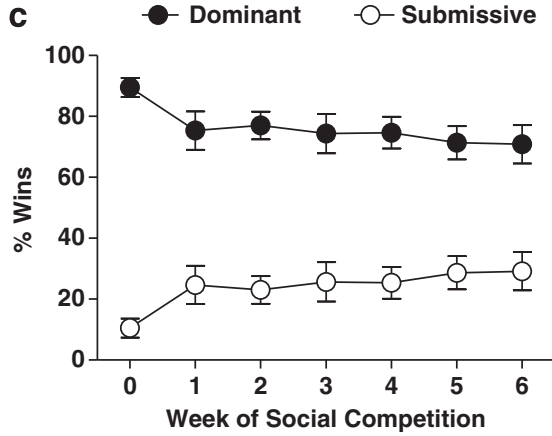
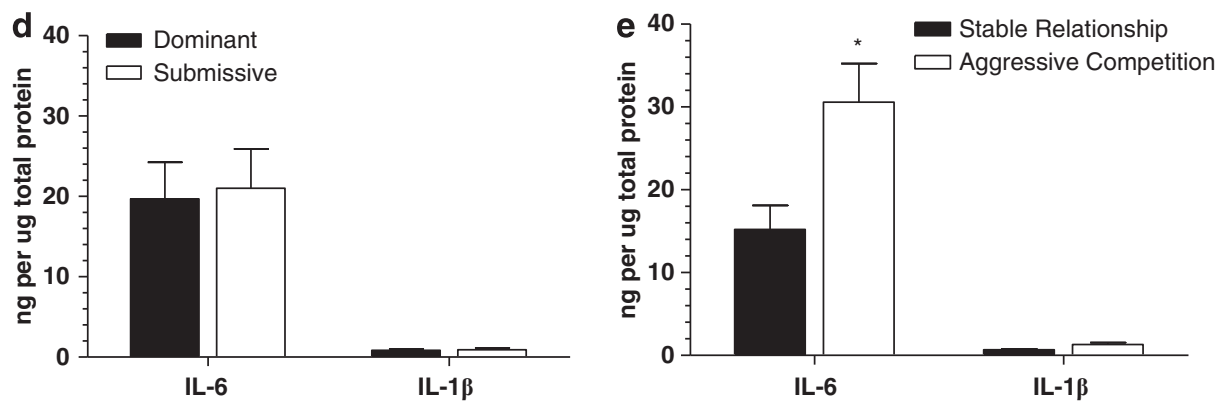

Figure 1 Elevations of interleukin-6 (IL-6) in rat cortex are a key feature of depressive-like behavior induced by stress. (a) Sprague-Dawley rats exposed to inescapable footshock $(n=18)$ demonstrated helpless behavior indicated by an increase in the $\%$ of response failures in an active-avoidance paradigm relative to sham controls $(n=12)$. A subset of rats subjected to inescapable footshock were resilient to the effects of inescapable footshock $(n=5)$. (b) Protein levels of IL- 6 were increased in the cortex of helpless rats relative to sham controls in the absence of elevations in IL-1 $\beta$, while a trend for reduced IL- 6 was observed in the resilient cohort ( $n=3-4$ per treatment group). (c) Dominant-submissive relationships observed over a 6 -week period in rats competing for a food reward ( $n=6$ per group). (d) No significant increases in IL-6 or IL-1 $\beta$ in the cortex of submissive subjects relative to dominant subjects ( $n=6$ per treatment group). (e) In competing pairs in which the hierarchy was unstable and rats continued to fight for dominance, both subjects of the pair demonstrated significant elevations of IL-6 in the absence of IL-1 $\beta$ in the cortex relative to pairs in which dominance level was stable $\left({ }^{*} P<0.05 ; n=6\right.$ per treatment group).

There were no meaningful differences in IL-1 $\beta$ protein levels in the cortex across treatment groups following one-way ANOVA $(F(2,11)=0.3181 ; P>0.05$; Figure $1 b)$.

Figure $1 \mathrm{c}$ illustrates the dominant-submissive relationship between pair-housed rats competing for food over a period of 6 weeks. Two-way ANOVA with Bonferroni post hoc comparisons revealed a significant dominance level by time interaction $(F(6,70)=2.665 ; P<0.05)$ in which there was a main effect of dominance $(P<0.05)$ and no significant effect of time indicating that over the 6-week period the level of dominance was maintained. Further analyses revealed that of the groups of competing pairs $(n=6), 50 \%$ maintained the original level of dominance, while the other $50 \%$ of the pairs demonstrated aggressive interactions such that the rat of the pair that was initially submissive in the early weeks of competitions began to compete aggressively with the dominant rat. Initial analysis of cortex homogenates from dominant rats relative to submissive rats did not reveal any differences in IL- 6 or IL- $1 \beta$ protein levels $(P>0.05$; Figure 1d). However, stratification of dominance level for pairs in which the original level of dominance was maintained (stable) vs pairs in which the submissive rat was competing aggressively with the dominant rat (aggressive) revealed a significant increase in IL-6 in both the dominant and submissive rat within the pairs in which the dominant-submissive relationship was no longer stable ( $t$-test: $P<0.05$ vs stable; Figure $1 \mathrm{e}$ ), and in the absence of alterations in IL-1 $\beta$.
Central administration of IL-1 $\beta$ induces sickness and depressive-like behavior and elevations of IL-6. It has been previously reported that IL-1 $\beta$ induces depressive-like behaviors with accompanying increases in 'sickness behavior' and elevations of IL- 6 in rodents. ${ }^{23,26}$ Reassuringly, we were able to confirm and extend these observations. IL-1 $\beta$ (50-200 ng, $2 \mathrm{~h}$ pretreatment, i.c.v.) produced dose-dependent increases in immobility time as analyzed by one-way ANOVA with Dunnett's post hoc comparisons in the tail suspension test $(\mathrm{F}(3,82)=4.864 ; P<0.01$ vs vehicle; Figure $2 \mathrm{a})$ and forced swim test $(F(3,68)=3.251 ; P<0.05$ vs vehicle; Figure $2 \mathrm{~b}$ ), an effect suggestive of a prodepressive profile. IL-1 $\beta$-treated mice also demonstrated dose-related increases in sickness behaviors $(F(3,59)=41.54 ; P<0.0001$ vs vehicle; Figure $2 \mathrm{c}$ ). Cortex homogenates of mice administered IL-1 $\beta$ (100 ng, i.c.v.) revealed significant increases in IL-1 $\beta$ protein levels relative to vehicle-infused controls ( $t$-test: $P<0.001$ vs vehicle; Figure $2 \mathrm{~d}$ ), as well as a significant increases in IL- 6 protein levels ( $t$-test: $P<0.001$ vs vehicle; Figure 2e).

Central administration of IL-6 induces depressive-like behavior in the absence of sickness or elevations in IL-1 $\beta$. To understand the role of IL- 6 in the depressive and sickness behavior observed after administration of IL-1 $\beta$, we evaluated the direct central effects of IL-6. Central administration of IL-6 (500-1000 ng, i.c.v.; 2 h pretreatment) to naïve 

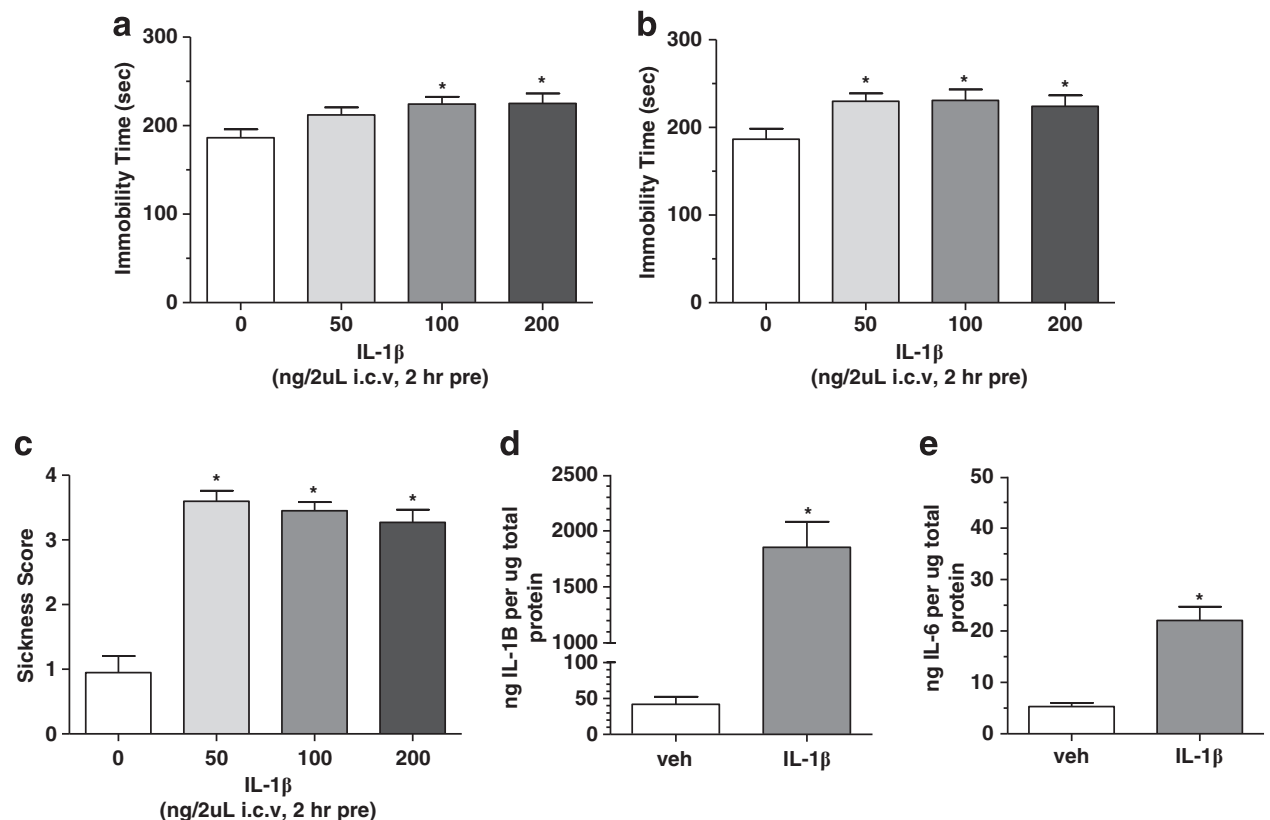

Figure 2 Effects of central administration of recombinant mouse interleukin-1 1 (IL-1 $\beta$ ) to Swiss Webster mice. (a) IL-1 $\beta$ produced dose-dependent increases in immobility time in the tail suspension and (b) forced swim test indicative of a depressive-like effect $\left({ }^{*} P<0.05\right.$ vs vehicle-treated control; $\left.n=\right)$. (c) IL- $1 \beta$ produced significant increases in sickness behavioral score at the same doses that produce depressive-like behaviors $\left({ }^{*} P<0.05\right.$ vs vehicle-treated control; $n=15-26$ per treatment group). (d) Central administration of recombinant mouse IL-1 $1 \beta$ produced significant increases in IL-1 $1 \beta$ protein levels in the cortex of mice as measured via multiplex enzyme-linked immunosorbent assay (ELISA) ( ${ }^{*} P<0.05 ; n=4-6$ per treatment group). (e) Central administration of recombinant mouse IL-1 $\beta$ produced significant increases in IL-6 protein levels in the cortex of mice as measured via multiplex ELISA ( ${ }^{*} P<0.05 ; n=4-6$ per treatment group). I.c.v., intracerebroventricularly; veh, vehicle.

mice produced dose-dependent increases in immobility time as analyzed by one-way ANOVA with Dunnett's post hoc comparisons in the tail suspension $(\mathrm{F}(3,37)=2.998 ; P<0.05$ vs vehicle; Figure $3 a$ ) and forced swim tests $(\mathrm{F}(3,48)=2.272 ; P<0.05$ vs vehicle; Figure $3 \mathrm{~b})$, indicative of depressive-like activity of IL-6. Central administration of IL6 at doses that increased immobility did not produce significant increases in sickness behaviors $(F(3,37)=1.342$; $P>0.05$ vs vehicle; Figure $3 c$ ) or alterations in general exploratory behavior in an open field (Supplementary Figures S1 and S2). Importantly, as measured by multiplex ELISA, cortex homogenates revealed the expected increase in IL-6 protein levels in IL-6-treated mice $(1 \mu \mathrm{g}$, i.c.v.) relative to vehicle controls ( $P<0.05$ vs vehicle; Figure $3 \mathrm{~d})$, which were not accompanied by significant increases in $\mathrm{IL}-1 \beta$ protein $(P>0.05$ vs vehicle; Figure $3 e)$. The duration of depressivelike behavior in the tail suspension test following IL-6 administration ( $1 \mu \mathrm{g}$, i.c.v.) was sustained for up to $48 \mathrm{~h}$ as indicated by a statistically significant increase in immobility time relative to vehicle-treated control as measured by $t$-test at each timepoint $\left({ }^{*} P<0.05\right.$ vs vehicle within timepoint; Figure 3f). The sustained depressive-like behavioral phenotype does not appear to be a result of regionally specific upregulation of IL- 6 following i.c.v. administration $(1 \mu \mathrm{g}, 24 \mathrm{~h}$ pretreatment), as statistically significant increases in IL-6 protein expression were observed in the hippocampus ( $t$-test: $P<0.05$ vs vehicle; Figure $3 g$ and Supplementary Figure $3 a$ ), hypothalamus ( $t$-test: $P<0.05$ vs vehicle; Figure $3 \mathrm{~h}$ and Supplementary Figure 3b) and frontal cortex ( $t$-test: $P<0.05$ vs vehicle; Figure $3 \mathrm{i}$ and Supplementary Figure $3 \mathrm{c}$ ), with modest nonsignificant increases also observed in the striatum ( $t$-test: $P=0.06$ vs vehicle; Figure $3 \mathrm{j}$ and Supplementary Figure $3 d$ ). Consistent with a sustained depressive-like phenotype, $24 \mathrm{~h}$ pretreatment of IL-6 $(1 \mu \mathrm{g}$, i.c.v.) produced a significant reduction in social interaction behavior relative to vehicle-infused controls ( $t$-test: $P<0.05$; Figure $3 \mathrm{k})$. The reduction in total investigation time of the female mouse by IL-6-treated males was not a result of a general reduction in exploratory behaviors as the mean latency to interact with the stimulus female mouse was not significantly different relative to vehicle-treated males ( $t$-test: $P>0.05$; Figure $3 \mathrm{k}$ ).

Depressive-like phenotype and reduced antidepressantlike efficacy in a mouse model with endogenous overexpression of IL-6. To further test the hypothesis that central elevation of IL- 6 protein is a relevant mechanism of depressive-like behavior, we employed LPR mice that have previously been reported to have increased IL-6 mRNA expression in brain regions, and a depressive-like phenotype relative to control MRL WT mice. ${ }^{55,56,57,58}$ In the tail suspension (Figure $4 a$ ) and forced swim tests (Figure $4 b$ ), LPR mice spent significantly more time immobile relative to MRL WT controls ( $t$-test: $P<0.05$ ), whereas locomotor activity in the open field was not different between MRL and LPR mice (data not shown).

Critically, IL-6 protein levels of naïve LPR mice were significantly elevated relative to MRL WT controls in both the hippocampus ( $t$-test: $P<0.05$; Figure $4 \mathrm{c}$ ) and frontal cortex ( $t$-test: $P<0.05$; Figure $4 d$ ).

Following administration to MRL mice, fluoxetine produced robust antidepressant-like effects in both the tail suspension 

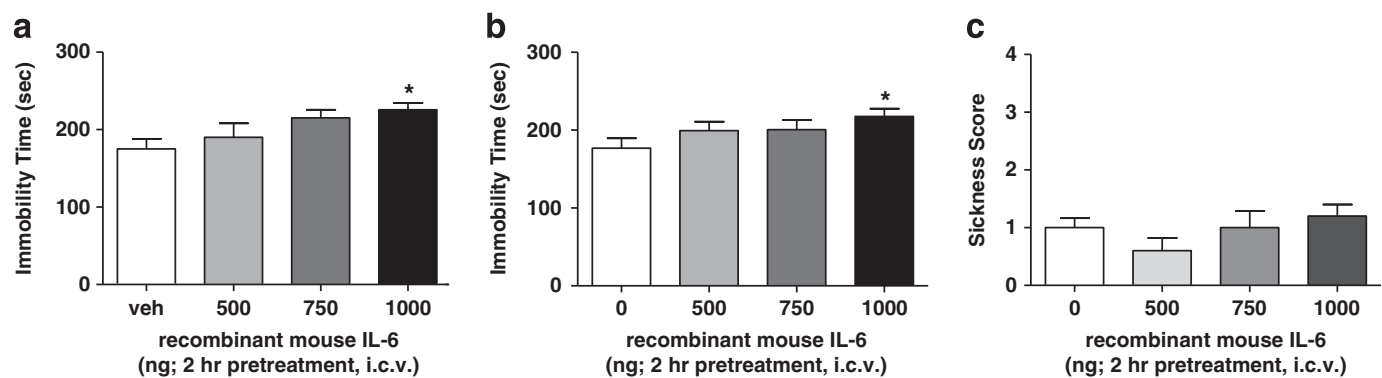
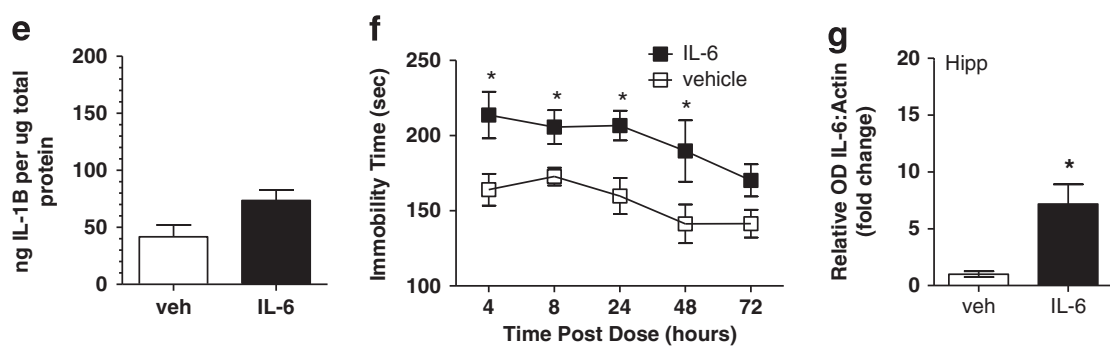
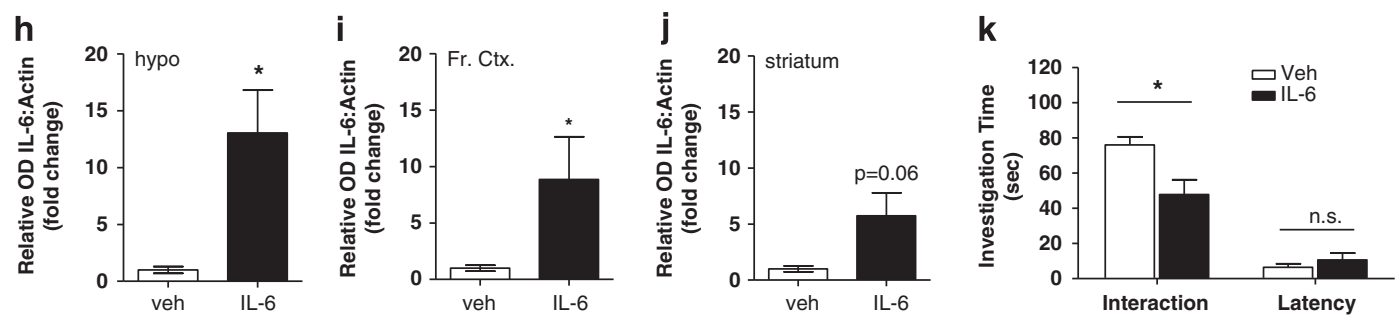

Figure 3 Effects of central administration of recombinant mouse interleukin-6 (IL-6) to Swiss Webster mice. (a) IL-6 produced dose-dependent increases in immobility time in the tail suspension and (b) forced swim tests indicative of a depressive-like effect ( ${ }^{*} P<0.05$ vs vehicle-treated control; $n=9-15$ per treatment group). (c) IL-6 did not produce increases in sickness behavioral score at doses that produce depressive-like behaviors. (d) Central administration of recombinant mouse IL-6 produced significant increases in IL-6 protein levels in the cortex of mice as measured via multiplex enzyme-linked immunosorbent assay (ELISA) ( ${ }^{*} P<0.05 ; n=4-6$ per treatment group). (e) IL$1 \beta$ protein levels were not significantly elevated in the cortex following central administration of recombinant mouse IL-6 as measured via multiplex ELISA $\left({ }^{*} P>0.05 ; n=4-6\right.$ per treatment group). (f) A single dose of $1 \mu \mathrm{g}$ recombinant mouse IL-6 (intracerebroventricularly (i.c.v.)) produces significant increases in immobility time in the tail suspension test up to $48 \mathrm{~h}$ post administration, indicative of a sustained depressive-like effect ${ }^{*} P<0.05$ vs vehicle-treated control at each timepoint; $n=6-12$ per treatment group per timepoint). Twenty-four hour pretreatment of recombinant mouse IL-6 into the left lateral ventricle ( $1 \mu \mathrm{g}$, i.c.v.) produces significant increases in IL- 6 protein levels across brain regions relative to vehicle-infused controls as demonstrated in (g) the hippocampus, (h) the hypothalamus, (i) the frontal cortex and (j) nonsignificant increases in the striatum $\left({ }^{*} P<0.05\right.$ vs vehicle; $n=4$ per treatment group per brain region). (k) Central administration of IL-6 ( $24 \mathrm{~h}$ pretreatment) produced reductions in social interaction behavior as measured by investigation time of an intact female stimulus mouse relative to vehicle-treated controls $\left({ }^{*} P<0.05\right.$ vs vehicle-treated control within trial analysis; $n=16-17$ per treatment group), with no significant differences in initial reaction to a female stimulus mouse (latency) indicating no impairment in general exploratory behavior in IL-6-treated mice relative to vehicle-treated controls.

$(F(3,33)=7.708 ; P<0.001$ vs vehicle; Figure $4 \mathrm{e})$ and forced swim test $(F(3,50)=14.38 ; P<0.0001$ vs vehicle; Figure $4 f)$ as analyzed by one-way ANOVA within MRL vs vehicletreated control. In contrast, evaluation of the antidepressantlike effects of fluoxetine administered to LPR mice revealed an overall significant effect of fluoxetine treatment as measured by one-way ANOVA within LPR in the tail suspension test $(F(3,39)=3.315 ; P<0.05$; Figure $4 \mathrm{e})$ and forced swim test $(\mathrm{F}(3,42)=11.55 ; P<0.05$; Figure $4 \mathrm{f})$; however, Dunnett's post hoc comparisons revealed statistically significant reductions in immobility time at only the highest doses tested, thereby indicating a blunted response to fluoxetine's antidepressant-like effects in LPR mice relative to WT MRL controls. These differences in the response to fluoxetine were not a result of differences in serotonin transporter levels or differences in serotonin transporter occupancy or pharmacokinetics of fluoxetine across the two strains (Supplementary Tables 1-3, respectively).
Elevated IL- 6 levels in the brain following exogenous administration alter the ability of fluoxetine to produce an antidepressant-like effect. To determine whether the blunted effects of fluoxetine in LPR mice was specifically due to elevated IL-6 levels, we next assessed the effects of fluoxetine following exogenous IL-6 administration to Swiss Webster mice. Fluoxetine $(60 \mathrm{~min}$ pretreatment, intraperitoneally) produced the expected dose-dependent reductions in immobility time in vehicle-infused controls (i.c.v., $24 \mathrm{~h}$ pretreatment) as analyzed by one-way ANOVA with Dunnett's post hoc comparisons vs vehicle/vehicle control $(\mathrm{F}(2,41)=2.272 ; \quad P>0.05 \quad$ vs vehicle/vehicle control; Figure $4 \mathrm{~g}$ ), indicative of an antidepressant-like effect. Pretreatment with IL-6 (1000 ng i.c.v., $24 \mathrm{~h}$ pretreatment) blocked the ability of fluoxetine to produce an antidepressant-like response relative to the robust antidepressant-like effects of fluoxetine in vehicle-infused controls, with only the highest dose of fluoxetine $\left(56 \mathrm{mg} \mathrm{kg}^{-1}\right)$ producing a 

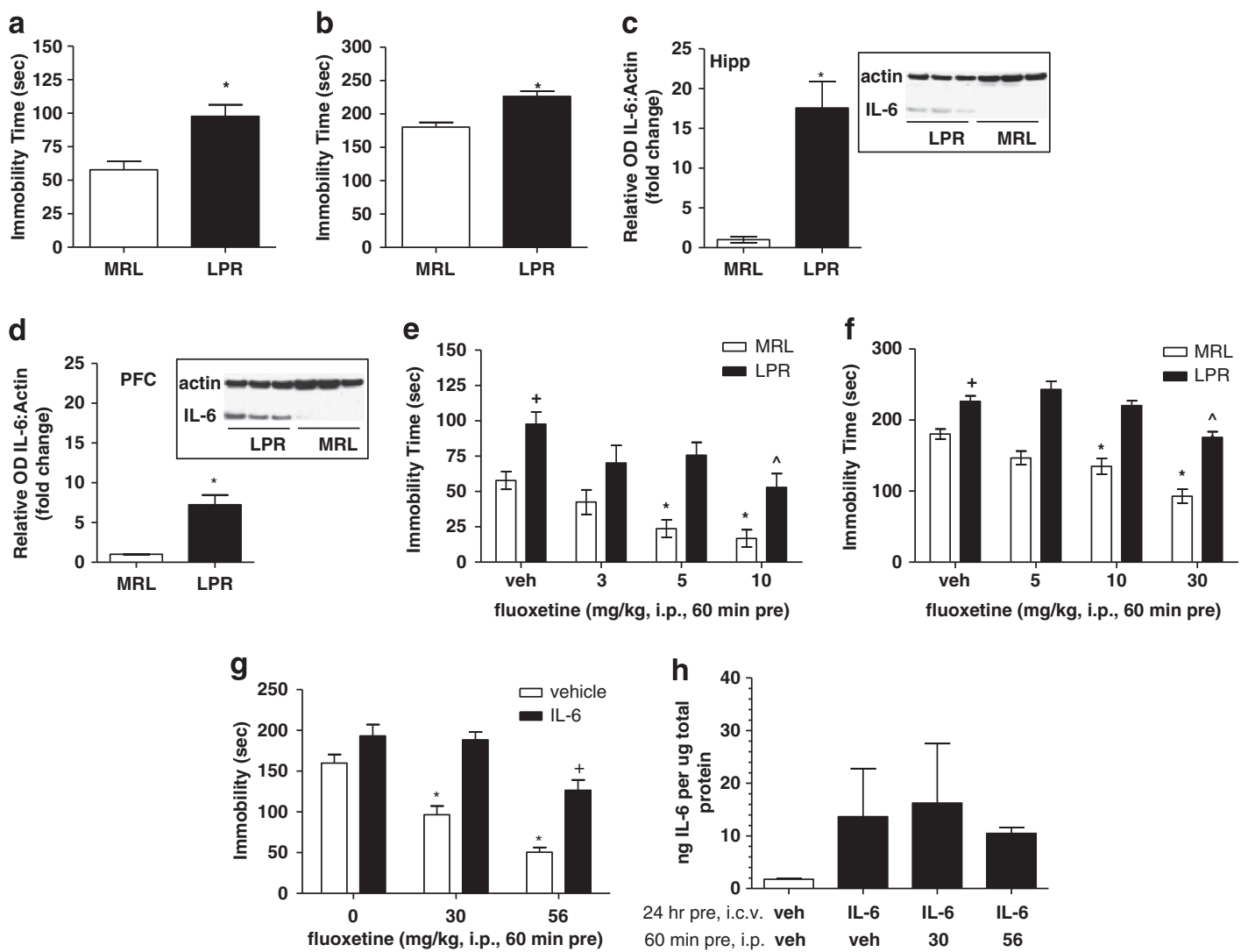

Figure 4 Overexpression of interleukin-6 (IL-6) in the central nervous system (CNS) results in depressive-like behavior and reduced efficacy of antidepressant treatment. (a) LPR mice demonstrate increases in immobility time in the tail suspension and (b) forced swim tests, indicative of a depressive-like effect $\left({ }^{*} P<0.05\right.$ vs MRL control; $n=8$ per genotype). (c) LPR mice demonstrate significant increases in IL-6 protein levels relative to MRL wild-type (WT) controls in the hippocampus and (d) prefrontal cortex as measured by the western blot analysis ( $n=3$ per genotype). (e) In the tail suspension test, vehicle (veh)-treated LPR mice demonstrated significant increases in immobility time relative to MRL control mice $\left({ }^{+} P<0.05\right.$ vs vehicle-treated MRL control. Acute administration of fluoxetine produced dose-dependent and significant reductions in immobility time in MRL mice relative to vehicle-treated control at doses at 5 and $10 \mathrm{mg} \mathrm{kg}^{-1}$ indicative of an antidepressant-like effect $\left({ }^{*} P<0.05\right.$ vs vehicle-treated MRL control; $n=8-9$ per treatment group). Acute administration of fluoxetine to LPR mice produced only antidepressant-like effects at $10 \mathrm{mg} \mathrm{kg}^{-1}(\wedge P<0.05 \mathrm{vs}$ vehicle-treated LPR control; $n=8-10$ per treatment group). (f) In the forced swim test, vehicle-treated LPR mice demonstrated significant increases in immobility time relative to MRL control mice $\left({ }^{+} P<0.05\right.$ vs vehicle-treated MRL control). Acute administration of fluoxetine produced dose-dependent and significant reductions in immobility time in MRL mice relative to vehicle-treated control at doses at 10 and $30 \mathrm{mg} \mathrm{kg}^{-1}$ indicative of an antidepressant-like effect $\left({ }^{*} P<0.05\right.$ vs vehicle-treated MRL control; $n=12-13$ per treatment group). Acute administration of fluoxetine to LPR mice produced only antidepressant-like effects at $30 \mathrm{mg} \mathrm{kg}^{-1}(\wedge P<0.05$ vs vehicle-treated LPR control; $n=9-11$ per treatment group). (g) Consistent with results observed for the reduced response of fluoxetine in mice with endogenous overexpression of IL-6 in the CNS, fluoxetine administered to mice that were pretreated $24 \mathrm{~h}$ prior with centrally administered IL-6 also demonstrated a similar reduced response to the antidepressant-like effects of fluoxetine relative to the robust response observed in vehicle-infused mice ( $n=8-17$ per treatment group). In mice centrally administered vehicle control (24 $\mathrm{h}$ pre), fluoxetine produced significant reductions in immobility in the tail suspension test at 30 and $56 \mathrm{mg} \mathrm{kg}^{-1}$ ( ${ }^{*} P<0.05 \mathrm{vs}$ veh/veh-treated control). In mice centrally administered IL-6 ( $24 \mathrm{~h}$ pre), fluoxetine produced only significant reductions in immobility time at $56 \mathrm{mg} \mathrm{kg}^{-1}\left({ }^{+} P<0.05 \mathrm{vs} \mathrm{IL-6/veh-treated} \mathrm{mice)}\right.$. (h) Central administration of IL-6 (24 h pre) produced increases in IL-6 protein levels in the brain, which was not attenuated by fluoxetine treatment $(n=4$ per treatment group). I.c.v., intracerebroventricularly; i.p., intraperitoneally; $\mathrm{OD}$, optical density.

significant reduction in immobility time as analyzed by one-way ANOVA with Dunnett's post hoc comparisons vs IL-6/vehicle control $(\mathrm{F}(2,40)=7.759 ; P<0.05$; Figure $4 \mathrm{~g})$. Brain homogenates revealed a sustained elevation of IL-6 protein levels in the IL- 6 + fluoxetine groups that were only partially attenuated by fluoxetine treatment (Figure 4h).

Blockade of IL-6-induced increases in protein levels and depressive-like behavior by central administration of anti-IL-6 antibody. To demonstrate a direct and specific interaction of IL-6 in mediating depressive-like behavior, the effects of central coadministration of anti-IL-6 antibody $(1 \mu \mathrm{g})$ with IL-6 (1 $\mu \mathrm{g})$ were evaluated. IL-6 administration produced the expected increase in immobility time relative to vehicle/ vehicle-treated controls (Figure 5a). Although two-way ANOVA did not demonstrate a statistically significant main effect of IL-6 treatment $(\mathrm{F}(1,40)=3.86 ; P=0.056)$, planned post hoc comparisons revealed a statistically significant increase in immobility time in vehicle-treated mice in the presence of IL-6 relative to vehicle-treated mice coadministered vehicle $(P<0.05$; Figure 5a). Importantly, coadministration of anti-IL- 6 antibody with IL- 6 prevented the increases in immobility time observed when IL- 6 was coadministered with vehicle as measured by two-way ANOVA $(\mathrm{F}(1,40)=1.23 ; P>0.05$; Figure $5 \mathrm{~b})$. IL-6 protein levels from 

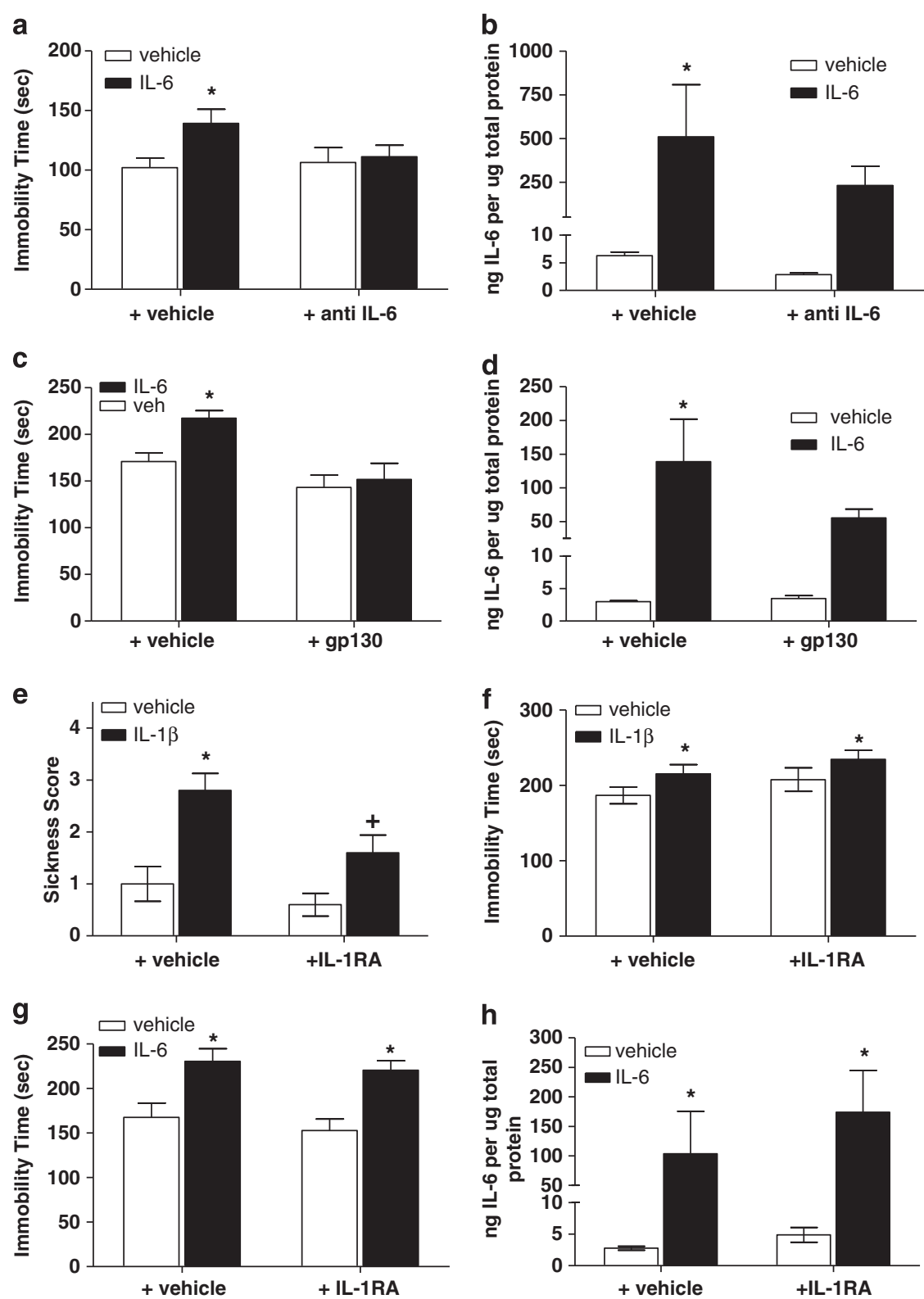

Figure 5 Modulation of interleukin-6 (IL-6)-induced signaling in the central nervous system (CNS) blocks IL-6-induced increases in protein levels and depressive-like behavior in Swiss Webster mice independent of IL-1. (a) Pretreatment with anti-IL-6 antibody (1 $\mu \mathrm{g}$, intracerebroventricularly (i.c.v.)) prevented the increase in IL-6-induced immobility $\left({ }^{\star} P<0.05\right.$ vs vehicle (veh)/veh-treated control; $n=10-11$ per treatment group) and (b) attenuated IL-6-induced increases in protein in the cortex relative to IL-6 coadministered with vehicle control indicating a direct and specific interaction at the receptor level ( ${ }^{*} P<0.05$ vs veh/veh-treated control; $n=3-4$ per treatment group). (c) Coadministration of an Fc chimera of soluble gp 130 prevented the IL-6-induced increases in immobility observed when IL- 6 was coadministered with vehicle $\left({ }^{*} P<0.05\right.$ vs veh/ veh-treated control; $n=6-9$ per treatment group) and (d) produced an attenuation of IL-6 protein in cortex $\left({ }^{\star} P<0.05\right.$ vs veh/veh-treated control; $n=3-6$ per treatment group). (e) Pretreatment with the IL-1 receptor antagonist (IL-1RA) $\left(1 \mu \mathrm{g}\right.$, i.c.v.) blocked the IL-1 $\beta$-induced increases in sickness behaviors $\left({ }^{*} P<0.05 \mathrm{vs}\right.$ veh/veh-treated control; ${ }^{+} P<0.05$ vs veh/LL-1 $\beta ; n=10$ per treatment group) but (f) failed to attenuate the IL-1 $\beta$-induced increases in immobility time in the tail suspension test $\left({ }^{*} P<0.05\right.$ vs veh/veh-treated control; $n=10$ per treatment group). (g) Central administration of IL-6 (1 $\mu$ g, i.c.v.) produced the expected increase in immobility time in the tail suspension test indicative of a depressive-like phenotype, which was not blocked by pretreatment of IL-1RA ( $1 \mu$ g, i.c.v.) $\left({ }^{*} P<0.05\right.$ vs veh/veh-treated controls; $n=8-12$ per treatment group). (h) The IL-1 antagonist IL-1RA fails to block IL-6-induced increases in IL-6 protein levels in the cortex as measured by enzyme-linked immunosorbent assay (ELISA) ( ${ }^{\star} P<0.05$ vs veh/veh-treated controls; $n=3-4$ per treatment group).

brain homogenates demonstrate a significant main effect of IL-6 $(\mathrm{F} 91,11)=8.112 ; P<0.05 \mathrm{IL}-6 /$ vehicle vs vehicle/ vehicle). Coadministration of anti-IL-6 antibody with IL-6 produced a modest attenuation of $\mathrm{IL}-6$ levels $(F(1,11)$ $=1.207 ; P>0.05$; Figure 5b).
Administration of soluble gp130 FC blocks central IL-6induced protein levels and depressive-like behavior by interfering with trans-signaling. We have evaluated and proven the direct and specific ability to block an IL-6induced effect of depressive-like behavior at the receptor level 
in our experimental paradigm, but the ability to interfere with the IL-6 trans-signaling pathway is also of high interest from both a mechanistic and therapeutic standpoint. Administration of IL-6 produced the expected increase in immobility time relative to vehicle/vehicle-treated controls. Although two-way ANOVA did not demonstrate a statistically significant main effect of IL-6 treatment $(F(1,23)=3.66$; $P=0.06$ ), planned post hoc comparisons revealed a statistically significant increase in immobility time in vehicletreated mice in the presence of IL- 6 relative to vehicletreated mice coadministered vehicle $(P<0.05$; Figure $5 c)$. Coadministration of gp130 with IL-6 prevented the increases in immobility time observed when IL-6 was coadministered with vehicle $(\mathrm{F}(1,23)=10.47 ; \quad P<0.01)$. IL-6 protein levels from brain homogenates as analyzed by two-way ANOVA with planned Bonferroni's post hoc comparisons demonstrated a significant main effect of IL-6 $(F(1,14)$ $=10.69 ; P<0.05$ IL-6/vehicle vs vehicle/vehicle). Coadministration of gp130 with IL-6 produced a nonsignificant attenuation of IL-6 levels $(F(1,14)=2.08 ; P>0.05$; Figure $5 \mathrm{~d})$.

\section{IL-6-induced depressive-like behavior is not blocked by} IL-1 receptor antagonism. To provide additional evidence to support the hypothesis that IL-6 produces depressive-like behaviors independent of the IL-1 pathway, central administration of the IL-1RA was evaluated in the presence of IL- $1 \beta$ or IL- 6 . Coadministration of a maximally soluble

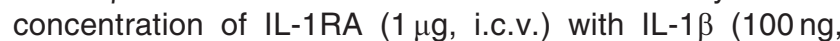
i.c.v.) produced a significant attenuation of IL-1 $\beta$-induced sickness behaviors indicating a functionally relevant dose of IL-1RA. As expected, analysis by two-way ANOVA with Bonferroni's post hoc comparisons revealed a statistically significant main effect of IL-1 $\beta(\mathrm{F}(1,36)=20.51 ; P<0.0001$; Figure $5 e)$. Coadministration of IL-1RA to IL-1 $\beta$-treated mice produced a statistically significant attenuation of the increases in sickness behaviors observed when IL-1 $\beta$ was coadministered with vehicle $(\mathrm{F}(1,36)=6.698 ; P<0.05$; Figure 5e). With respect to immobility time, two-way ANOVA with Bonferroni's post hoc comparisons revealed a statistically significant main effect of IL-1 $\beta(F(1,36)=4.69$; $P<0.05$; Figure 5f). Coadministration of IL-1RA to IL-1 $\beta$ treated mice failed to alter immobility time relative to immobility times observed when IL-1 $\beta$ was coadministered with vehicle $(\mathrm{F}(1,360=2.453 ; P>0.05$; Figure $5 f)$. Coadministration of IL-1RA (1 $\mu$ g, i.c.v.) to IL-6-treated mice $(1 \mu \mathrm{g}$, i.c.v.) failed to block the increases in immobility time produced by IL-6 coadministered with vehicle. As expected, two-way ANOVA with Bonferroni's post hoc comparisons revealed a statistically significant main effect of IL-6 $(\mathrm{F}(1,38)=22.05 ; P<0.0001$; Figure $5 \mathrm{~g})$. Coadministration of IL-1RA to IL-6-treated mice failed to alter immobility time relative to immobility times observed when IL- 6 was coadministered with vehicle $(\mathrm{F}(1,38)=0.796 ; \quad P>0.05$; Figure $5 \mathrm{~g}$ ). IL-6 protein levels from cortex homogenates by two-way ANOVA with Bonferroni's post hoc comparisons demonstrate a significant main effect of IL-6 $(\mathrm{F}(1,10)=$ 10.19; $P<0.05$ IL-6/vehicle vs vehicle/vehicle; Figure $5 \mathrm{~h}$ ). Coadministration of IL-1RA with IL-6 failed to alter IL-6induced increases in IL-6 protein levels $(F(1,10)=0.733$; $P>0.05$; Figure 5h).

\section{Discussion}

The present results demonstrate that elevations in IL-6 levels in the brain contribute to a depressive-like phenotype in rodents and also provide evidence that sustained IL-6 activation prevents the ability of selective serotonin reuptake inhibitors to produce antidepressant-like responses. These data further demonstrate a distinct and specific behavioral phenotype of IL- 6 relative to IL-1 $\beta$. In addition, the present data suggest that modulation of the IL-6 pathway may provide therapeutic strategies for treating treatment-resistant depression.

Given the clinical data reports suggesting elevations in IL-6 and IL-1 $\beta$ in plasma levels of patients with MDD, we were intrigued to evaluate IL- 6 and IL-1 $\beta$ protein levels utilizing a number of well-characterized rodent models demonstrating depressive-like behaviors following stress. ${ }^{9,13-15}$ Rats subjected to inescapable footshock stress demonstrated helplessness, a form of behavioral despair, as indicated by a lack of escape response in an escape-avoidance task. Consistent with previous reports, in our studies only $77 \%$ of subjects met the criteria of 'helpless' as defined by a failure rate of $\geqslant 50 \%$ during escape-avoidance testing. ${ }^{59}$ The modest increase in IL- 6 levels in the absence of elevated IL- $1 \beta$ in the helpless rats relative to the nonshocked controls provided evidence that IL6 contributes to the helpless phenotype in this model while IL$1 \beta$ does not. It was also of interest to evaluate the brain cytokine levels of the cohort of subjects exposed to the same inescapable footshock stress that did not become helpless (resilient). Relative to the helpless rats, there was a reduced level of brain IL-6 in the resilient group. This is particularly interesting given that IL- 6 knockout mice have been reported to show a stress-resistant phenotype and specifically do not demonstrate helpless behavior in a similar paradigm of inescapable shock, whereas in the same study helpless WT mice demonstrated significant increases in IL-6 mRNA in hippocampus. ${ }^{60}$ In addition to learned helplessness, we selected a model that exploits submissive behavior in a social competition assay, which may be reflective of the social withdrawal component of MDD. ${ }^{37}$ Although the a priori expectation was that submissive animals would have elevated brain cytokine levels relevant to their dominant counterparts, this was not the case; as the subjects were stratified by the level of dominance, we found that in pairs in which the submissive rat had begun to compete aggressively with the dominant rat over time, there were significant increases in IL-6 relative to IL-6 levels assessed from pairs in which the dominant remained dominant and the submissive remained submissive throughout the course of the experiment.

Central administration of species-homologous $\mathrm{IL}-1 \beta$ or species-homologous IL- 6 to naive mice resulted in depressive-like behaviors, as indicated by increased immobility times in both the forced swim and tail suspension tests. The IL-1 $\beta$ induced depressive-like phenotype was accompanied by increased sickness behaviors similar to the behavioral effects induced by LPS, ${ }^{29-36}$ whereas the IL-6-induced depressive-like phenotype was not. Importantly, analysis of brain tissue homogenates from IL-1 $\beta$-infused mice revealed the expected increases in IL-1 $\beta$ protein that were also associated with large increases in brain IL-6 levels, while IL-6-infused mice were 
without significant increases in brain IL-1 $\beta$ protein. The present findings are the first report, to our knowledge, of a specific range of doses of recombinant mouse IL-6 (administered centrally to mice) necessary to induce depressive-like behaviors. Mixed findings on the ability of IL- 6 administration to produce sickness and/or depressive-like behaviors have been reported with most of these studies focusing on a peripheral route of administration and with various nonspecies homologous proteins (that is, human recombinant administered to rodents). ${ }^{39-44}$ In the present studies, we specifically utilized only recombinant mouse IL- 6 and IL- $1 \beta$ as a way to control for the immune response, which could be induced by nonspecies homologous proteins as well as specifically evaluating the effects of IL-6 following central administration. The lack of sickness behavior in IL-6-treated mice in the present studies may be related to the fact that IL-1 $\beta$ increases did not result from IL- 6 administration, thereby suggesting that activation of IL-1 $\beta$ or its downstream effectors may be responsible for the general proinflammatory sickness states. Further characterization of IL-6-induced depressive-like behavior revealed an interesting time course with a single dose of $1 \mu \mathrm{g}$ i.c.v. demonstrating significant increases in immobility time up to a timepoint of $48 \mathrm{~h}$ post dose relative to vehicle-infused controls as well as social deficits $24 \mathrm{~h}$ post dose and without any accompanying sickness behavior.

As another means to test the hypothesis that central elevation of IL-6 protein is a relevant mechanism of depressivelike behavior, we employed the LPR mouse model, which has been utilized historically for the study of autoimmune diseases (for example, lupus), as at approximately 12 weeks of age these mice exhibit the typical signs of autoimmune disease. ${ }^{61,62}$ Interestingly, the comorbidity between systemic lupus erythmatosus (SLE) and MDD is extremely high and alterations in IL-6 are prominently featured during the course of SLE such that elevations of IL-6 levels in the cerebrospinal fluid of SLE patients is highly correlated with the presentation of neuropsychiatric symptoms. ${ }^{63}$ Further, SLE patients often present with MDD symptoms before the onset of autoimmune antibodies and formal diagnosis of SLE. ${ }^{64}$ Owing to the nature of the documented accelerated disease progression in LPR mice, mice evaluated in the present studies were restricted to an age range of $8-11$ weeks at the time of testing. ${ }^{65}$ The robust increases in immobility time in the LPR mice relative to the MRL mice in this study were consistent with the findings of Gao and co-workers, ${ }^{57}$ and importantly the relationship observed for the increase in immobility time relative to the increased IL-6 protein expression in the brain of LPR mice provided additional evidence in support of our hypothesis that elevations of IL- 6 in the CNS are a key mediator of depressive behavior.

We then looked to understand the functional significance of elevated IL- 6 levels in the brain as a factor in the response to antidepressant treatment. The most intriguing finding from these experiments was the reduced ability of the selective serotonin reuptake inhibitor fluoxetine to produce an antidepressant-like effect in LPR mice relative to the robust dosedependent response of fluoxetine in MRL WT controls, which were not a result of endogenous differences in serotonin transporter levels, serotonin transporter occupancy or pharmacokinetic differences between the two strains. To further confirm these observations, we evaluated the response to fluoxetine in mice centrally administered IL- 6 at a timepoint that was more relevant to a nonacute effect. Given the window of increased immobility time, demonstrated to be in excess of $48 \mathrm{~h}$ following a single dose of $1 \mu \mathrm{g} \mathrm{IL-6}$, a 24-h pretreatment period of IL- 6 was selected to represent a nonacute recapitulation of a pathological elevation of IL-6 in the CNS. Fluoxetine administered to mice that were pretreated $24 \mathrm{~h}$ prior with IL-6 also demonstrated a similar reduced response relative to the robust response observed in vehicle-infused mice. These data suggest that increased IL- 6 levels in the CNS may be related to treatment-resistant depression and are in line with clinical findings that demonstrate that IL-6 levels remain elevated in plasma of MDD patients who fail to respond to antidepressant therapy. ${ }^{22}$

The final objectives of this study were aimed to evaluate the ability to modulate the IL-6 pathology by strategically interfering with the production and maintenance of IL- 6 via manipulation of the IL- 6 signal-transduction pathway. Direct antagonism by anti-IL- 6 antibody blocked the ability of IL-6 to induce a depressive-like phenotype and attenuated the IL-6-induced increases in brain IL-6 protein likely via blocking the ability of IL6 to bind to its cognate receptor. A second strategy for modulating IL-6-induced increases involved administration of an Fc monomer of gp130. Coadministration of gp130 with IL-6 produced a meaningful blockade of the IL-6-induced increase in immobility time with a significant reduction in IL-6 protein levels in brain extracts. By increasing the availability of circulating soluble gp130 with the Fc monomer, it is likely that this exogenous molecule served as a decoy for IL-6, thereby preventing the soluble IL-6 receptor complex to dimerize with membrane-bound gp130. ${ }^{66}$ Finally, as a means to provide further evidence that IL-6 produces depressive-like behavior independent of IL-1, we demonstrated the failure of the IL-1 antagonist IL-1RA to attenuate both IL-1 $\beta$ - and IL-6-induced depressive-like behavior, consistent with our working hypothesis that IL-1 $\beta$-induced depressive-like behaviors are likely mediated via downstream mechanisms (for example, nuclear factor- $\kappa B$ activation) resulting in the upregulation of IL- 6 , thus leading to an IL-6-induced depressive-like phenotype, while IL$1 \beta$-induced sickness behaviors are specific to the IL-1 $\beta$ activation.

From a translational perspective, the findings from the present studies demonstrating that elevations in IL-6 may have a pathophysiological role underlying depression and more specifically resistance to current classes of antidepressant medications lend greater support for the concepts of personalized medicine and patient stratification in the clinic. While monoaminergic-type therapeutics are likely successful for MDD patients in whom the underlying pathophysiology is monoaminergic alterations, then it is plausible to speculate that there are subsets of MDD patients (likely treatment resistant to monoaminergic type of therapies) in whom the pathophysiology of depression may be of a neuroimmune nature (for example, IL-6). Therefore, the ability to identify and prescreen patients for relevant biomarkers will be an important consideration for identifying novel therapeutic agents for treatment-resistant patients. Taken together, these data indicate that depressive-like behavior may be related to elevated levels of IL- 6 in the CNS and suggest that modulation 
of the IL-6 signaling pathway by way of preventing de novo IL-6 production may have therapeutic potential for treatmentresistant depression.

\section{Conflict of interest}

SJSR, SJN, ZAH, MB, SR-L and NJB were full timeemployees of Pfizer (formerly Wyeth Research) at the inception of this work and have no conflict of interest. SJSR conducted this work as part of her doctoral thesis through University College London, which was fully funded by Pfizer (formerly Wyeth Research) under the direction of her thesis advisor Dr Stephen J Moss. SJM received compensation as a member of the scientific advisory board of Pfizer (formerly Wyeth) and has consulted for GSK, Sepracor and SAGE therapeutics. SR-L is currently owner of IVS Pharma. NJB is currently employed by Astra Zeneca.

Acknowledgements. We wish to acknowledge Dr Menelas Pangalos, Dr Lee Schechter and Dr John Dunlop for support of this research, Dr Ildiko Antal and Dr Jeffrey D Kennedy for expert guidance, Ms Deborah Smith, Ms Kari Fonseca and $\mathrm{Mr}$ Brian Platt for exceptional technical assistance, and Ms Katherine E Fisher for critical review of this manuscript.

1. Smith RS. The macrophage theory of depression. Med Hypothesis 1991; 35: 298-306.

2. Maes M. Evidence for an immune response in major depression: a review and hypothesis Prog Neuropsychopharmacol Biol Psychiatry 1995; 19: 11-38.

3. Rush AJ, Trivedi MH, Wisniewski SR, Nierenberg AA, Stewart JW, Warden D et al. Acute and longer-term outcomes in depressed outpatients requiring one or several treatment steps: a STAR*D report. Am J Psychiatry 2006; 163: 1905-1917.

4. Warden D, Rush AJ, Trivedi MH, Fava M, Wisniewski SR. The STAR ${ }^{\star} D$ Project results: a comprehensive review of findings. Curr Psychiatry Rep 2007; 9: 449-459.

5. Maes M, Bosmans E, De Jongh R, Kenis G, Vandoolaeghe E, Neels H. Increased serum $\mathrm{IL}-6$ and $\mathrm{IL}-1$ receptor antagonist concentrations in major depression and treatment resistant depression. Cytokine 1997; 9: 853-858.

6. Maes M. Major depression and activation of the inflammatory response system. Adv Exp Med Biol 1999; 461: 25-45

7. Kim Y-K, Na K-S, Shin K-H, Jung H-Y, Choe S-H, Kim J-B. Cytokine imbalance in the pathophysiology of major depressive disorder. Prog Neuropsychopharmacol Biol Psychiatry 2007; 31: 1044-1053.

8. Simon NM, McNamara K, Chow CW, Maser RS, Papakostas GI, Pollack MH et al. A detailed examination of cytokine abnormalities in major depressive disorder. Eur Neuropsychopharmacol 2008; 18: 230-233.

9. Dowlati Y, Herrmann N, Swardfager W, Liu H, Sham L, Reim EK et al. A meta-analysis of cytokines in major depression. Biol Psychiatry 2010; 67: 446-457.

10. Loftis JM, Huckans M, Morasco BJ. Neuroimmune mechanisms of cytokineinduced depression: current theories and novel treatment strategies. Neurobiol Dis 2010; 37: 519-533.

11. Schiepers OJ, Wichers MC, Maes M. Cytokines and major depression. Prog Neuropsychopharmacol Biol Psychiatry 2005; 29: 201-217.

12. Raison CL, Capuron L, Miller AH. Cytokines sing the blues: inflammation and the pathogenesis of depression. Trends Immunol 2006; 27: 24-31.

13. Zorrilla EP, Luborsky L, McKay JR, Rosenthal R, Houldin A, Tax A et al. The relationship of depression and stressors to immunological assays: a meta-analytic review. Brain Behav Immun 2001; 15: 199-226.

14. Mossner R, Mikova O, Koutsilieri E, Saoud M, Ehlis AC, Muller N et al. Consensus paper of the WFSBP Task Force on Biological Markers: biological markers in depression. World $J$ Biol Psychiatry 2007; 8: 141-174.

15. Howren MB, Lamkin DM, Suls J. Associations of depression with C-reactive protein, IL-1, and IL-6: a meta-analysis. Psychosom Med 2009; 71: 171-186.

16. Lindqvist D, Janelidze S, Hagell $P$, Erhardt S, Samuelsson M, Minthon L et al. Interleukin-6 is elevated in the cerebrospinal fluid of suicide attempters and related to symptom severity. Biol Psychiatry 2009; 66: 287-292.

17. Yoshimura R, Hori H, Ikenouchi-Sugita A, Umene-Nakano W, Ueda N, Nakamura J. Higher plasma interleukin-6 (IL-6) level is associated with SSRI- or SNRI-refractory depression. Prog Neuropsychopharmacol Biol Psychiatry 2009; 33: 722-726.

18. Basterzi AD, Aydemir C, Kisa C, Aksaray S, Tuzer V, Yazici K et al. IL-6 levels decrease with SSRI treatment in patients with major depression. Hum Psychopharmacol 2005; 20 473-476.
19. Leo R, Di Lorenzo G, Tesauro M, Razzini C, Forleo GB, Chiricolo G et al. Association between enhanced soluble CD40 ligand and proinflammatory and prothrombotic states in major depressive disorder: pilot observations on the effects of selective serotonin reuptake inhibitor therapy. J Clin Psychiatry 2006; 67: 1760-1766.

20. Hannestad J, Dellagioia N, Bloch M. The effect of antidepressant medication treatment on serum levels of inflammatory cytokines: a meta-analysis. Neuropsychopharmacology 2011; 36: 2452-2459.

21. Słuzewska A, Rybakowski JK, Laciak M, Mackiewicz A, Sobieska M, Wiktorowicz K. Interleukin-6 serum levels in depressed patients before and after treatment with fluoxetine. Ann NY Acad Sci 1995; 762: 474-476.

22. O'Brien SM, Scully P, Fitzgerald P, Scott LV, Dinan TG. Plasma cytokine profiles in depressed patients who fail to respond to selective serotonin reuptake inhibitor therapy. $J$ Psychiatr Res 2007; 41: 326-331.

23. Kent S, Kelley KW, Dantzer R. Effects of lipopolysaccharide on food-motivated behavior in the rat are not blocked by an interleukin-1 receptor antagonist. Neurosci Lett 1992; 145 : 83-86

24. Hayley S, Mangano E, Strickland M, Anisman H. Lipopolysaccharide and a social stressor influence behaviour, corticosterone and cytokine levels: divergent actions in cyclooxygenase-2 deficient mice and wild type controls. J Neuroimmunol 2008; 197: 29-36.

25. Dantzer R, O'Connor JC, Freund GG, Johnson RW, Kelley KW. From inflammation to sickness and depression: when the immune system subjugates the brain. Nat Rev Neurosci 2008; 9: 46-56.

26. Koo JW, Duman RS. IL-1beta is an essential mediator of the antineurogenic and anhedonic effects of stress. Proc Natl Acad Sci USA 2008; 105: 751-756.

27. Fu X, Zunich SM, O'Connor JC, Kavelaars A, Dantzer R, Kelley KW. Central administration of lipopolysaccharide induces depressive-like behavior in vivo and activates brain indoleamine 2,3 dioxygenase in murine organotypic hippocampal slice cultures. J Neuroinflammation 2010; 7: 43

28. Painsipp E, Köfer MJ, Sinner F, Holzer P. Prolonged depression-like behavior caused by immune challenge: influence of mouse strain and social environment. PLoS One 2011; 6 : e20719.

29. Hart BL. Biological basis of the behavior of sick animals. Neurosci Biobehav Rev 1988; 12 : 123-137.

30. Kent S, Bluthé RM, Kelley KW, Dantzer R. Sickness behavior as a new target for drug development. Trends Pharmacol Sci 1992; 13: 24-28.

31. Aubert A, Vega C, Dantzer R, Goodall G. Pyrogens specifically disrupt the acquisition of a task involving cognitive processing in the rat. Brain Behav Immun 1995; 9: 129-148.

32. Dantzer R, Bluthé RM, Layé S, Bret-Dibat JL, Parnet P, Kelley KW. Cytokines and sickness behavior. Ann NY Acad Sci 1998; 840: 586-590.

33. Watkins LR, Maier SF. The pain of being sick: implications of immune-to-brain communication for understanding pain. Annu Rev Psychol 2000; 51: 29-57.

34. Dantzer R. Cytokine-induced sickness behavior: mechanisms and implications. Ann NY Acad Sci 2001; 933: 222-234.

35. Kelley KW, Bluthé RM, Dantzer R, Zhou JH, Shen WH, Johnson RW et al. Cytokineinduced sickness behavior. Brain Behav Immun 2003; 17: S112-S118.

36. Dantzer R, Kelley KW. Twenty years of research on cytokine-induced sickness behavior. Brain Behav Immun 2007; 21: 153-160.

37. American Psychiatric Association Diagnostic and Statistical Manual of Mental Disorders. 4th edn American Psychiatric Association: Washington, DC, 1994

38. Raison $\mathrm{CL}$, Demetrashvili M, Capuron L, Miller AH. Neuropsychiatric adverse effects of interferon-alpha: recognition and management. CNS Drugs 2005; 19: 105-123.

39. Zalcman S, Green-Johnson JM, Murray L, Nance DM, Dyck D, Anisman H et al. Cytokinespecific central monoamine alterations induced by interleukin-1, -2 and -6. Brain Res 1994; 643: 40-49

40. Brebner K, Hayley S, Zacharko R, Merali Z, Anisman H. Synergistic effects of interleukin1 beta, interleukin- 6 , and tumor necrosis factor-alpha: central monoamine, corticosterone, and behavioral variations. Neuropsychopharmacology 2000; 22: 566-580.

41. Connor TJ, Song C, Leonard BE, Merali Z, Anisman H. An assessment of the effects of central interleukin-1beta, $-2,-6$, and tumor necrosis factor-alpha administration on some behavioural, neurochemical, endocrine and immune parameters in the rat. Neuroscience 1998; 84: 923-933.

42. Oitzl MS, van Oers H, Schöbitz B, de Kloet ER. Interleukin-1 beta, but not interleukin-6, impairs spatial navigation learning. Brain Res 1993; 613: 160-163.

43. Lenczowski MJ, Bluthé RM, Roth J, Rees GS, Rushforth DA, van Dam AM et al. Central administration of rat IL-6 induces HPA activation and fever but not sickness behavior in rats. Am J Physiol 1999; 276: R652-R658.

44. $\mathrm{Wu} \mathrm{TH}$, Lin $\mathrm{CH}$. IL-6 mediated alterations on immobile behavior of rats in the forced swim test via ERK1/2 activation in specific brain regions. Behav Brain Res 2008; 193 183-191.

45. LeMay LG, Vander AJ, Kluger MJ. The effects of psychological stress on plasma interleukin-6 activity in rats. Physiol Behav 1990; 47: 957-961.

46. Shizuya K, Komori T, Fujiwara R, Miyahara S, Ohmori M, Nomura J. The influence of restraint stress on the expression of mRNAs for IL- 6 and the IL-6 receptor in the hypothalamus and midbrain of the rat. Life Sci 1997; 61: 135-140.

47. Shizuya K, Komori T, Fujiwara R, Miyahara S, Ohmori M, Nomura J. The expressions of mRNAs for interleukin-6 (IL-6) and the IL-6 receptor (IL-6R) in the rat hypothalamus and midbrain during restraint stress. Life Sci 1998; 62: 2315-2320. 
48. Audet MC, Mangano EN, Anisman H. Behavior and pro-inflammatory cytokine variations among submissive and dominant mice engaged in aggressive encounters: moderation by corticosterone reactivity. Front Behav Neurosci 2010; 156: 1-12.

49. Xiu LJ, Lin HM, Wei PK. The effect of chronic mild stress on tumor-bearing rats' behavior and its mechanism. Neurosci Lett 2010; 473: 1-4.

50. Monje FJ, Cabatic M, Divisch I, Kim EJ, Herkner KR, Binder BR et al. Constant darkness induces IL-6-dependent depression-like behavior through the NF- $\kappa B$ signaling pathway. J Neurosci 2011; 31: 9075-9083.

51. Sukoff Rizzo SJ, Wetzler C, Rosenzweig-Lipson S. Antidepressant induced alterations of submissive behavior in a social competition model in Lewis rats. Society for Neuroscience Meeting Planner 2007 Program No. 334.2 Online.

52. Ring RH, Malberg JE, Potestio L, Ping J, Boikess S, Luo B et al. Anxiolytic-like activity of oxytocin in male mice: behavioral and autonomic evidence, therapeutic implications. Psychopharmacology (Berl) 2006; 185: 218-225.

53. Steru L, Chermat R, Thierry B, Simon P. The tail suspension test: a new method for screening antidepressants in mice. Psychopharmacology (Berl) 1985; 85: 367-370.

54. Macbeth AH, Edds JS, Young WS III. Housing conditions and stimulus females: a robust social discrimination task for studying male rodent social recognition. Nat Protoc 2009; 4: 1574-1581.

55. Tomita M, Holmana BG, Santoro TJ. Aberrant cytokine gene expression in the hippocampus in murine systemic lupus erythematosus. Neurosci Lett 2001; 302: 129-132.

56. Tsai C-Y, Wu T-H, Huang SF, Sun KH, Hsieh SC, Han SH et al. Abnormal splenic and thymic IL-4 and TNF- expression in MRL-Ipr/Ipr mice. Scand J Immunol 2006; 41: 157163.

57. Gao HX, Campbell SR, Cui MH, Zong P, Hee-Hwang J, Gulinello M et al. Depression is an early disease manifestation in lupus-prone MRL/lpr mice. J Neuroimmunol 2009; 207: 45-56.

58. Sakić B, Szechtman H, Braciak T, Richards C, Gauldie J, Denburg JA. Reduced preference for sucrose in autoimmune mice: a possible role of interleukin-6. Brain Res Bull 1997; 44: 155-165.
59. Cryan JF, Mombereau C. In search of a depressed mouse: utility of models for studying depression-related behavior in genetically modified mice. Mol Psychiatry 2004; 9: 326-357.

60. Chourbaji S, Urani A, Inta I, Sanchis-Segura C, Brandwein C, Zink M et al. IL-6 knockout mice exhibit resistance to stress-induced development of depression-like behaviors. Neurobiol Dis 2006; 23: 587-594.

61. Gulinello M, Putterman C. The MRL/lpr mouse strain as a model for neuropsychiatric systemic lupus erythematosus. J Biomed Biotechnol 2011; 2011: 207504.

62. Adachi M, Watanabe-Fukunaga R, Nagata S. Aberrant transcription caused by the insertion of an early transposable element in an intron of the Fas antigen gene of Ipr mice. Proc Natl Acad Sci USA 1993; 90: 1756-1760.

63. Strous RD, Shoenfeld Y. Behavioral changes in systemic lupus erythematosus are of an autoimmune nature. Nat Clin Pract Rheumatol 2007; 3: 592-593.

64. Fragoso-Loyo H, Richaud-Patin Y, Orozco-Narváez A, Dávila-Maldonado L, AtishaFregoso $\mathrm{Y}$, Llorente $\mathrm{L}$ et al. Interleukin-6 and chemokines in the neuropsychiatric manifestations of systemic lupus erythematosus. Arthritis Rheum 2007; 56: 1242-1250.

65. Dixon FJ, Andrews BS, Eisenberg RA, McConahey PJ, Theofilopoulos AN, Wilson CB. Etiology and pathogenesis of a spontaneous lupus-like syndrome in mice. Arthritis Rheum 1978; 21: 64-67.

66. Ward LD, Howlett GJ, Discolo G, Yasukawa K, Hammacher A, Moritz RL et al, High affinity interleukin-6 receptor is a hexameric complex consisting of two molecules each of interleukin-6, interleukin-6 receptor, and gp-130. J Biol Chem 1994; 69: 23286-23289.

Translational Psychiatry is an open-access journal published by Nature Publishing Group. This work is licensed under the Creative Commons Attribution-NonCommercial-No Derivative Works 3.0 Unported License. To view a copy of this license, visit http://creativecommons.org/licenses/by-nc-nd/3.0/

Supplementary Information accompanies the paper on the Translational Psychiatry website (http://www.nature.com/tp) 